\title{
The fate of bio-carbon in FCC co-processing products
}

\author{
Gabriella Fogassy, Nicolas Thegarid, Yves Schuurman and Claude Mirodatos
}

\begin{abstract}
A promising alternative to the first generation of bio-fuels is to produce mixed bio- and fossil fuels by co-processing mixtures of biomass pyrolysis oil with crude oil fractions obtained from distillation in a conventional oil refinery. This was demonstrated to be technically feasible for fluid catalytic cracking (FCC), which is the main refinery process for producing gasoline. However, co-processing leads to more coke formation and to a more aromatic gasoline fraction. A detailed understanding is necessary on how the oxygenated moieties effect the reaction mechanism to further improve the process/catalysts. Moreover, for technical and marketing reasons, it is absolutely required to accurately determine the proportion of renewable molecules in the commercialized products. The carbon-14 method (also called radiocarbon or ${ }^{14} \mathrm{C}$ ) has been used as the most accurate and powerful method to discriminate fossil carbon from biocarbon, since fossil fuel is virtually ${ }^{14} \mathrm{C}$-free, while biofuel contains the present-day "natural" amount of

${ }^{14} \mathrm{C}$. This technique has shown that not all FCC products share bio-carbon statistically. The coke formed during a FCC cycle and to a lesser extent the gases are found richer in ${ }^{14} \mathrm{C}$ than gasoline. This result gives valuable information on the co-processing mechanism, supporting that the bio-oil oxygenated molecules are processed more easily at the expenses of the crude oil hydrocarbons, favouring the bio-coke and the bio-light gases production.
\end{abstract}

\section{Introduction}

In the next decades to come, due to market and environmental concerns supported by international regulations, alternative resources will progressively, but partly, substitute fossil crude oil for the production of fuels and chemicals. Among the main candidates are natural gas, coal and biomass, while only fuels produced from biomass can secure the energy supply in the long term, since they are renewable. In addition, they do not contribute to an increase of the global $\mathrm{CO}_{2}$ emission, ${ }^{1}$ as no transformation of stored fossil carbon takes place.

In 2003, the European Commission has issued a directive for sustainable transportation fuels in addition to the European objectives for primary energy (i.e., electricity and heat). According to the directive, the target for the share of biofuels is $2 \%$ in 2005 , increasing to $5.75 \%$ in 2010 , and possibly to even higher shares in 2020 (i.e., $10 \%$ is suggested). ${ }^{2}$

In order to meet these regulation constraints for transportation fuels, several strategies have been explored, one of which is the blending of fossil fuels with pure bio-fuels such as FAME or bio-ethanol. A promising alternative is to produce hybrid bio/ fossil fuels by co-processing mixtures of pyrolysis oil (produced from biomass) ) $^{3,4}$ and crude oil fractions (obtained from distillation) in a standard oil refinery. Such a scenario permits adjusting

IRCELYON, Institut de Recherches sur la Catalyse et l'Environnement de Lyon, UMR5256 CNRS-Université de Lyon1, 2 Avenue Albert Einstein,69626Villeurbanne, France.E-mail: yves.schuurman@ircelyon.univ-lyon1.fr; Fax: +33472445 399; Tel: +33472445399 the content of renewable carbon in the produced fuels (gasoline or diesel) according to the regularly evolving regulations in the domain. 5

Fluid catalytic cracking (FCC) is the most important conversion process used in petroleum refineries, since over $50 \%$ of the refinery's heavy petroleum goes through the FCC unit for processing. Its principal aim is to convert high molecular weight hydrocarbons obtained from crude oil distillation into more valuable products, mainly gasoline. The co-processing technique adapted to FCC was demonstrated to be technically feasible at lab- and pilot-scale. ${ }^{6-10}$ Thus, the gasoline produced by co-processing of hydrodeoxygenated pyrolysis oil (HDO-oil) with conventional vacuum gas oil (VGO) in a labscale FCC unit was shown in our group to lead to gasoline yields and qualities quite close to the products obtained by processing pure VGO feedstocks. ${ }^{9,10}$ However, a key feature not been addressed till now is how to determine accurately the proportion of renewable molecules in the targeted products to be commercialized, i.e., the gasoline fraction. As a matter of fact, if all or most of the co-processed bio-carbon coming from the bio-oils is released as $\mathrm{CO}_{2}$ or light gases, which means absent or depleted from the produced gasoline, the marketing of "bio-fuels" may be a commercial challenge. Furthermore, the fate of the bio-carbon during the co-processing cycle is of utmost importance to understand the mechanism of the co-processing cracking step, when both the oxygenated molecules coming from the bio-oil and the hydrocarbon molecules coming from the VGO feedstock are admitted together onto the FCC catalysts to be cracked into lighter products. 
The radiocarbon method has been known for decades to provide an unequivocal means to distinguish between carbonaceous material of biological and fossil in origin. ${ }^{11}$ Eventually, concerning the biobased contents of natural range materials, the method has been developed to a standardized level ${ }^{12,13}$ - accelerator mass spectrometry (AMS) as one of the measuring techniques providing high precision and reliability.

In this study, the radiocarbon method by AMS has been used to determine the bio-carbon contents in the products obtained from the FCC co-processing of VGO and HDO-oil, according to a protocol developed in our group that we previously reported in ref. 9. This study is complementing a mechanistic approach of the co-processing step, recently reported in ref. 10 .

\section{Radiocarbon analysis}

Samples for radiocarbon dating are prepared for use in an accelerator mass spectrometer (AMS-PSI/ETH facility in Zurich ${ }^{14}$ ) by converting them into a solid graphite form. This is done by converting the samples into carbon dioxide through combustion then to carbon monoxide in the presence of zinc. Via a catalytic reaction with iron, carbon monoxide is further reduced into graphite. Combustion of the samples to convert them via $\mathrm{CO}_{x}$ into graphite, however, also introduces other elements into the sample like nitrogen. ${ }^{14}$

Graphite samples and reference materials are pressed onto a metal disc and then mounted on a target wheel so they can be analyzed in sequence. Ions from a cesium gun are then fired at the target wheel, producing negatively ionized carbon atoms. These negatively ionized carbon atoms pass through focusing devices and an injection magnet before reaching the tandem accelerator where they are accelerated to the positive terminal by a voltage difference of two million volts.

At this stage, other negatively charged atoms are unstable and cannot reach the detector. The negatively charged carbon atoms, however, move on to the stripper (a gas or a metal foil) where they lose the electrons and emerge as the triple, positively charged carbon atoms. At this stage, molecules that may be present are eliminated because they cannot exist in this triple charged state. The carbon atoms with triple positive charges further accelerate away from the positive terminal and pass through another set of focusing devices where mass analysis occurs. In mass analysis, a magnetic field is applied to these moving charged particles, which causes the particles to deflect from the path they are travelling. If the charged particles have the same velocity but different masses, as in the case of the carbon isotopes, the heavier particles are deflected least. Detectors at different angles of deflection then count the particles. ${ }^{12,14}$

\section{Determination of the bio-carbon content}

The radiocarbon contents are expressed as pMC (percent Modern Carbon). ${ }^{14}$ The fossil fuel samples are assumed to give a realistic figure of the process background and they are thus exploited to correct the background of the raw radiocarbon contents. The uncertainties are estimated based on the law of error propagation and are given by $1 \sigma$ confidence.
Table 1 Elemental composition of VGO and HDO-oil

\begin{tabular}{lll}
\hline Composition (wt \%) & VGO & HDO-oil \\
\hline Sulphur & 2.02 & - \\
Nitrogen & 0.07 & - \\
Hydrogen & 12.4 & 10 \\
Carbon & 85.4 & 69 \\
Oxygen & - & 21 \\
\hline
\end{tabular}

Radiocarbon contents of the fuel mixture is formed according to the ${ }^{14} \mathrm{C}$ balance equation

$$
\mathrm{pMC}_{\text {mixture }}=F_{\text {bio }} \mathrm{pMC}_{\text {bio }}+\left(1-F_{\text {bio }}\right) \mathrm{pMC}_{\text {fossil }}
$$

where $\mathrm{pMC}_{\text {mixture }}$ is the measured ${ }^{14} \mathrm{C}$ content of the fuel mixture, $\mathrm{pMC}_{\mathrm{bio}}$ and $\mathrm{pMC}_{\text {fossil }}$ are the ${ }^{14} \mathrm{C}$ content of the biomass derived and fossil components in the mixture, respectively, and $F_{\text {bio }}$ the fraction of the biomass derived carbon. The eqn (1) can be rearranged to obtain the bio-carbon fraction

$$
F_{\text {bio }}=\frac{\mathrm{pMC}_{\text {mixture }}-\mathrm{pMC}_{\text {fossil }}}{\mathrm{pMC}_{\text {bio }}-\mathrm{PMC}_{\text {fossil }}}
$$

Thus the bio-carbon fraction can be determined based on prior knowledge of $\mathrm{pMC}_{\text {fossil }}$ and $\mathrm{pMC}_{\mathrm{bio}}$ and by measuring the $\mathrm{pMC}_{\text {mixture }}$ We assume $\mathrm{pMC}_{\text {fossil }}=0$, since fossil fuel does not contain any radiocarbon and $\mathrm{pMC}_{\mathrm{bio}}$ is obtained by measuring the ${ }^{14} \mathrm{C}$ content of the biofuel used in the mixture.

\section{Co-processing experiments}

Co-processing experiments using $10 \mathrm{wt} \%$ HDO-oil and $90 \mathrm{wt} \%$ VGO experiments were performed in a fixed-bed quartz reactor (ID $=12 \mathrm{~mm}, L=340 \mathrm{~mm}$ ) equivalent to a micro activity test (MAT) reactor.

The physico-chemical properties of the HDO-oil and VGO feedstocks and the experimental results of processing (pure VGO) and co-processing (VGO + HDO-oil) have been described and compared in detail for various conversions. ${ }^{9,10}$ The HDO-oil was obtained by flash pyrolysis of pine wood residue. The filtered bottom phase fraction of the pyrolysis oil was hydrogenated at 290 bar and $330{ }^{\circ} \mathrm{C}$ over a carbon supported ruthenium catalyst. The elemental composition of the VGO and HDO-oil are given in Table 1.

A reaction cycle, mimicking a $\mathrm{FCC}$ cycle, consists of $1 \mathrm{~min}$ cracking at $500{ }^{\circ} \mathrm{C}, 18 \mathrm{~min}$ of stripping under argon flow at $500{ }^{\circ} \mathrm{C}, 40 \mathrm{~min}$ regeneration under $20 \mathrm{vol} \%$ of $\mathrm{O}_{2}$ in $\mathrm{Ar}$ at $650{ }^{\circ} \mathrm{C}$ and $11 \mathrm{~min}$ purge. For each experimental condition 4 cycles were run. 1 gram of equilibrated FCC catalyst was used. This industrial catalyst contains $15 \mathrm{wt} \%$ Y-zeolite, $2.5 \mathrm{wt} \%$ rare earth oxides, $240 \mathrm{ppm}$ of $\mathrm{Ni}$ and $870 \mathrm{ppm}$ of V. 0.33 gram of the liquid reaction mixture introduced into the reactor, giving a catalyst-to-oil ratio $(\mathrm{C} / \mathrm{O})$ of 3 . During the cracking and stripping steps, the liquid product was collected in a glass receiver located at the exit of the reactor and kept at $-50{ }^{\circ} \mathrm{C}$. Meanwhile, the gases were collected in a gasbag. Argon was used as a carrier gas (flow of $100 \mathrm{ml} \mathrm{min}^{-1}$ ).

The gases collected in gasbags during the cracking/stripping cycles were analyzed using an Agilent 3000A micro gas 
chromatograph equipped with three columns (molecular sieve $5 \mathrm{~A}(10 \mathrm{~m} \times 0.32 \mathrm{~mm})$, PoraPLOT-U $(8 \mathrm{~m} \times 0.32 \mathrm{~mm}), \mathrm{OV}-1$ $(8 \mathrm{~m} \times 0.15 \mathrm{~mm} \times 2 \mu \mathrm{m}))$ and a thermal conductivity detector for $\mathrm{H}_{2}, \mathrm{C} 1-\mathrm{C} 6$ hydrocarbons. He was used an internal standard.

Carbon containing products $\left(\mathrm{CO}\right.$ and $\left.\mathrm{CO}_{2}\right)$ obtained during catalyst regeneration were analyzed on-line by mass spectrometry for evaluating the coke deposition at each cycle. The mass spectrometer (VG-Prolab with a closed ion source) was regularly calibrated for $\mathrm{CO}$ and $\mathrm{CO}_{2}$ and $\mathrm{He}$ was used as an internal standard. Thermal gravimetric analysis on some samples gave similar coke yields. The error in the coke yield is estimated as less than $5 \%$.

Liquid samples collected over a series of FCC cycles were analyzed on a HP6890 gas chromatograph equipped with an ASTM-2887 system and analyzed according to their boiling point range. In refinery practice the product distribution is given in terms of groups mainly determined by their boiling point range: dry gas $\left(\mathrm{H}_{2}, \mathrm{CO}, \mathrm{CO}_{2}, \mathrm{C} 1-\mathrm{C} 2\right.$ hydrocarbons), liquefied petroleum gas (LPG: $\mathrm{C} 3-\mathrm{C} 4$ hydrocarbons), gasoline (C5-221 ${ }^{\circ} \mathrm{C}$ boiling point), light cycle oil (LCO: $221-370{ }^{\circ} \mathrm{C}$ boiling point), bottom fraction (boiling point $>370{ }^{\circ} \mathrm{C}$ ) and coke. The conversion is defined as the sum of the yields of dry gas, LPG, gasoline and coke.

The ${ }^{14} \mathrm{C}$ content has been determined of four samples, corresponding to the initial 10:90 HDO-oil-VGO liquid sample, the produced gas fraction, the liquid fraction and the solid spent catalyst. The gas fraction components (mixture of $\mathrm{C}_{1}-\mathrm{C}_{4}, \mathrm{H}_{2}, \mathrm{CO}_{2}$ ) were adsorbed on a column of zeolite $\mathrm{X}$. The four samples were pretreated by the AMS sample pre-treatment procedure reported by Hajdas et al. ${ }^{14}$

\section{Results}

As reported in ref. 9 and 10 co-processing of HDO-oil-VGO mixtures by catalytic cracking (with up to $20 \%$ of bio-oil) lead to practically similar gasoline yields, but to more coke, carbon dioxide and water production, with less hydrogen compared to processing of pure VGO.

Fig. 1 shows the product distribution for the cracking of VGO and the co-processing of the 10:90 HDO-oil-VGO mixture. Typically, for a conversion in the range of $66-71 \%$, the gasoline yield decreased from 46 to $43 \%$, the dry gas yield is increased from 1 to $2 \%$, the coke yield is increased from 3 to $5 \%$, the LPG yield is slightly increased from 16 to $21 \%$, the LCO and the bottom yield decreased. In previous experiments the conversion of the HDO-oil-VGO co-processing was similar or slightly lower than the pure VGO processing. Here, the conversion during co-processing is slightly higher (71 vs. 66\%). The lower gasoline yield and higher gas yield during co-processing of the 10 : 90 HDO-oil-VGO mixture compared to the VGO cracking (Fig. 1) might be partly due to some overcracking, although previous results showed that overcracking occurs at conversion levels above $75 \%$.

More detailed analyses of the gasoline fraction have shown that the gasoline composition is different in the case of HDOoil-VGO co-processing showing the presence of alkyl-phenols and more aromatic components. 9,10

Table 2 summarizes the data of the starting materials. Fossil fuel (VGO) is virtually ${ }^{14} \mathrm{C}$-free, while bio-oil (HDO-oil)

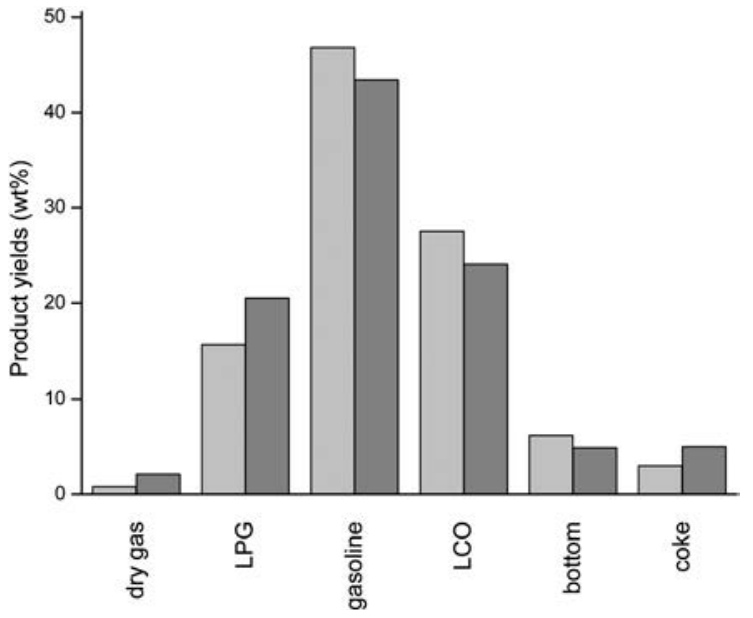

Fig. 1 Product yields (wt\%) of VGO cracking (light grey bars) and coprocessing of the 10/90 HDO-oil-VGO mixture (dark grey bars). Conditions: 1 gram equilibrated $\mathrm{FCC}$ catalyst, $\mathrm{C} / \mathrm{O}=3,500{ }^{\circ} \mathrm{C}$.

Table 2 Bio-carbon content of the starting materials

\begin{tabular}{lll}
\hline & \multicolumn{2}{l}{ Bio-carbon content (\%) } \\
\cline { 2 - 3 } Sample & Raw data (pMC) & Normalised to 100\% \\
\hline HDO-oil & $112.93 \pm 0.42 \%$ & $\begin{array}{l}100 \% \\
\text { VGO }\end{array}$ \\
10:90 HDO-oil-VGO & 0 & 0 \\
\hline
\end{tabular}

Table 3 Bio-carbon content of the co-processing products

\begin{tabular}{lll}
\hline & \multicolumn{2}{l}{ Bio-carbon content (\%) } \\
\cline { 2 - 3 } Fraction & Raw data (pMC) & Normalised to $100 \%$ \\
\hline Total liquid products & $8.446 \pm 0.08 \%$ & 7.5 \\
Gasoline $^{a}$ & & 7.2 \\
Coke & $17.83 \pm 0.12 \%$ & 15.8 \\
Gas & $11.94 \pm 0.1 \%$ & 10.6
\end{tabular}

${ }^{a}$ Calculated by subtraction of the unconverted feed assuming an biocarbon content of $8.5 \%$.

contains the present-day "natural" amount of ${ }^{14} \mathrm{C}$. The raw data ${ }^{14} \mathrm{C}$ content amounts to $112.93 \pm 0.42 \%$, e.g., larger than $100 \%$. This is due to fluctuations in the ${ }^{14} \mathrm{C}$ levels since 1950 . All the data reported here have been normalized with respect to this value. The normalized 14-carbon fraction of the starting 10:90 HDO-oil-VGO mixture amounts to $8.5 \%$. By using the carbon wt $\%$ of both HDO-oil and VGO (Table 1) this corresponds to $10.2 \mathrm{wt} \%$ of HDO-oil in the mixture, thus corresponding to a correct carbon mass balance.

Table 3 presents the bio-carbon content, expressed as the percentage of bio-carbon over the total amount of carbon (bio + fossil), in each fraction of the co-processing products determined separately. The latter are divided into three groups corresponding to the three different phases existing during the collection process:

1. Gas phase products: $\mathrm{CH}_{4}, \mathrm{C}_{2} \mathrm{H}_{6}, \mathrm{C}_{2} \mathrm{H}_{4}, \mathrm{C}_{3} \mathrm{H}_{8}, \mathrm{C}_{3} \mathrm{H}_{6}$, $\mathrm{C}_{4} \mathrm{H}_{10}, \mathrm{C}_{4} \mathrm{H}_{8}, \mathrm{C}_{4} \mathrm{H}_{6}+\mathrm{CO}_{2}, \mathrm{CO}$. 
2. Total liquid products: products from C5 hydrocarbons up to the heaviest liquid products (gasoline, LCO and bottom), including the unconverted liquid feed. From the known total conversion $(71 \%)$ the bio-carbon content of the gasoline of the FCC run can be determined.

3. Coke: carbonaceous residues deposited on the catalyst during the cracking step, and collected as $\mathrm{CO}_{2}$ during the catalyst regeneration step by combustion in air.

The experimental results reported above show that the initial $8.5 \%$ bio-carbon content of the mixed feed is not statistically distributed among the products. Thus, the gas and especially the coke fractions contain significantly more bio-carbon than expected from the statistical distribution $(10.6 \%$ and $15.8 \%$, respectively). In contrast the total liquid fraction (including unreacted feed) presents a bio carbon content lower than the initial feed content (7.5\%). After correction from the unconverted liquid fraction, which represents the LCO and bottom fraction and assuming it still contains the initial $8.5 \mathrm{wt} \%$ of biocarbon, the content of the liquid product, gasoline, is even lower at $7.2 \%$.

\section{Discussion}

The increase of coke formation under co-processing conditions can essentially be related to the presence of the HDO-oil. It is most likely formed from the condensation of bio-molecules coming from the ligno-cellulose degradation, which can easily polymerize (phenolic like) into polyaromatic coke precursors. This key role of oxygenated molecules in coke formation is confirmed by the relatively large content of bio-carbon in the coprocessing coke. However, as the coke formation is increased by $45 \%$ under co-processing conditions and as the bio-carbon contribution amounts to only $16 \%$ at maximum, a significant contribution to coke formation originates from the proper fossil VGO cracking. As a matter of fact, VGO cracking is markedly impacted during co-processing by the hydrogen deficit induced by the reduction of oxygenates into hydrocarbons and water. ${ }^{10}$ As a typical example, the alcohols are dehydrated into olefins and water. This hydrogen deficit favours a higher yield of aromatic and polyaromatic components, thus enhancing the coke formation.

The gas fraction increases by $35 \%$ during co-processing of a 10 : 90 HDO-oil-VGO mixture. As proposed in ref. 10, besides the coke formation, HDO-oil macromolecules are deeply cracked and converted into gaseous products, including a significant proportion of $\mathrm{CO}_{2}$ and $\mathrm{H}_{2} \mathrm{O}$. Due to the size of the oxygenated molecules, these degradation reactions occur essentially in the mesopores of the FCC catalyst, involving acid sites (essentially Lewis type, typical of extra-framework alumina deposits). A complex network of reactions, including alcohol dehydration and acid decarboxylation to produce the observed $\mathrm{CO}_{2}$ and $\mathrm{H}_{2} \mathrm{O}$, are involved in competition with the VGO cracking reactions (inhibited by preferential site occupancy by the polar bio-molecules). This explains the higher fraction of bio-carbon in the gaseous products and the lower one in the liquid products, which mainly derive from the intra-framework cracking of the fossil hydrocarbon molecules.

\section{Conclusions}

The radiocarbon method has been used to quantify the biocarbon fraction in the products of the co-processing of conventional vacuum gas oil with hydrodeoxygenated pyrolysis oil, giving unique information on the co-processing mechanism. The efficiency and accuracy of the method rank it as a powerful complement to the large panel of characterisation methods required to tackle this difficult domain of mixed bio- and fossilmixtures. $^{15}$

The direct relationship between bio-carbon and HDO-oil content allowed us to estimate the bio-carbon distribution among the co-processing products. Thus, the bio-carbon contained in the HDO-oil is concentrated mainly in the gas fraction $(10.6 \%)$ and in the coke fraction (15.8\%), while the targeted liquid product, gasoline, contains only around $7 \%$ of bio-carbon. Such an uneven bio-carbon distribution is explained by changes in the cracking routes during co-processing, arising essentially from the competitive adsorption of polar (oxygenates) and non-polar (hydrocarbons) molecules in the meso-porous volume of the FCC catalyst. Thus, the increase of the gas production at the expenses of the liquid fraction during co-processing as compared to pure VGO processing indicates that the molecules from HDOoil are cracked and deoxygenated into gases, which in turn inhibits the production of bottom, LCO and gasoline from VGO. The larger coke formation, richer in bio-carbon than expected from a statistical distribution, would come from the easy re-polymerisation of oxygenated lignocellulosic fragments (phenolics) into carbonaceous deposits. Another part of the coke increase would come from the depletion in hydrogen due to water formation, leading to the preferential formation of fossil polyaromatic coke precursors, further accumulating as coke deposits at the catalyst surface.

As a more general conclusion in terms of commercial and/or environmental perspectives, it can be stressed that co-processing of bio-oil with fossil resources like VGO leads to a bio-carbon impoverished gasoline, but a bio-carbon enriched LPG. This also questions the use of the ASTM D6866 protocol applied to fuels to verify the amount of renewables processed in a (bio) refinery. Rather the overall process needs to be taken into account.

\section{Acknowledgements}

The authors gratefully acknowledge the FP6 European integrated project "Co-processing of upgraded bio-liquids in standard refinery units" (BIOCOUP), contract no.: 518312 as well as ACENET (HECABIO) for partial financial support.

\section{Notes and references}

1 J. C. Serrano-Ruiz and J. A. Dumesic, Energy Environ. Sci., 2011, 4, $83-$ 99.

2 H. Boerrigter, H. P. Calis, D. J. Slort, H. Bodenstaff, A. J. Kaandorp, H. Den Uil and L. P. L. M. Rabou, Gas cleaning for integrated biomass gasification (BG) and Fischer-Tropsch (FT) systems. ECN Report C-04056, 2004. URL: www.ecn.nl, accessed November 2011.

3 Q. Zhang, J. Chang, T. J. Wang and Y. Xu, Energy Convers. Manage., 2007, 48, 87-92.

4 A. V. Bridgwater, Biomass Bioenergy, 2012, 38, 68-94. 
5 European Biofuels technology platform, http://www.biofuelstp.eu/legislation.html, accessed November 2011.

6 M. E. Domine, A. C. van Veen, Y. Schuurman and C. Mirodatos, ChemSusChem, 2008, 1, 179-183.

7 F. De Miguel Mercader, M. J. Groeneveld, S. R. A. Kersten, N. W. J. Way, C. J. Schaverien and J. A. Hogendoorn, Appl. Catal., B, 2010, 96, 57-66.

8 A. A. Lappas, S. Bezergianni and I. A. Vasalos, Catal. Today, 2009, 145, 55-62.

9 G. Fogassy, N. Thegarid, G. Toussaint, A. C. van Veen, Y. Schuurman and C. Mirodatos, Appl. Catal., B, 2010, 96, 476-486.

10 G. Fogassy, N. Thegarid, Y. Schuurman and C. Mirodatos, Energy Environ. Sci., 2011, 4, 5068-5076.
11 G. C. Clayton, J. R. Arnold and F. A. Patty, Science, 1955, 122, $751-753$.

12 American Society for Testing and Materials (ASTM), Standard test methods for determining the biobased content of solid, liquid, and gaseous samples using radiocarbon analysis, (Method D6866), ASTM International, West Conshohocken, Pennsylvania, USA, 2011.

13 I. J. Dijs, E. van de Windt, L. Kailoha and K. van der Borg, Radiocarbon, 2006, 48, 315-323.

14 I. Hajdas, G. Bonani, J. Thut, G. i. Leone, R. Pfenninger and C. Maden, Nucl. Instrum. Methods Phys. Res., Sect. B, 2004, 223-224, 267-271.

15 G. Fogassy, C. Lorentz, G. Toussaint, N. Thegarid, Y. Schuurman and C. Mirodatos, Environ. Progress Sustainable Energy, DOI: 10.1002/ ep10631. 